\title{
Role of transport network accessibility in the spread of COVID-19 - a case study in Savar Upazila, Bangladesh
}

\author{
Khandakar Hasan Mahmud, Bibi Hafsa, Raju Ahmed \\ Department of Geography and Environment, Jahangirnagar University, Savar, Bangladesh
}

\begin{abstract}
The aim of this research was to test the hypothesis that people in a typical high-transport zone are particularly vulnerable with respect to transmission of coronavirus disease 2019 (COVID-19), a new contagious disease that has rapidly developed into a highrisk global problem. A case study was carried out in Savar Upazila, a sub-district of the capital city Dhaka in Bangladesh, which is traversed by a prominent national highway (DhakaAricha-N5) that also passes the concentric industrial export processing zone surrounding Dhaka. This municipality is thus part of a high-density transport network with extensive economic activities. COVID-19 data were collected from local records at the Upazila Health Complex, while spatial data of the Savar Upazila, including the pertinent road network, were identified and digitized using geographical information systems software. The presence of COVID-19 in in Savar Upazila was found to be strongly associated with the reach and mechanism of transport networks (Pearson correlation $=0.76$ with $99 \%$ confidence interval).
\end{abstract}

\section{Introduction}

Infectious diseases usually spread rapidly and affects many people disrupting their daily activities and movement, which \author{
1342, Bangladesh. \\ E-mail: raju.45@geography-juniv.edu.bd \\ accessibility; Bangladesh. \\ See online Appendix for additional Table. \\ Received for publication: 30 October 2020. \\ Revision received: 22 January 2021. \\ Accepted for publication: 23 January 2021. \\ (C) Copyright: the Author(s), 2021 \\ Licensee PAGEPress, Italy \\ Geospatial Health 2021; 16:954 \\ doi:10.4081/gh.2021.954
}

Correspondence: Raju Ahmed, Postgraduate Researcher, Department of Geography and Environment, Jahangirnagar University, Savar, Dhaka-

Key words: COVID-19; transport network; graph theory; topology;

This article is distributed under the terms of the Creative Commons Attribution Noncommercial License (CC BY-NC 4.0) which permits any noncommercial use, distribution, and reproduction in any medium, provided the original author(s) and source are credited. sometimes lead to large-scale health emergencies, classified as pandemics or epidemics depending on their reach and severity (WHO, 2018). The history of infectious diseases affecting human lives dates back many centuries, for example, the Black Death in the $14^{\text {th }}$ Century that killed more than a third of the World's population and a hundred years ago, 1918-1920, the Spanish influenza pandemic affected every third person in the world ( $>500$ million), killing between $2 \%$ and $3 \%$ of those infected (Taubenberger and Morens, 2020).

A typical epidemic engulfs region after region due to the movement of inflected humans, and transport networks play a crucial role in this expansion. The efficiency, speed and reach of modern transport increases the vulnerability of people at risk along roads, rails, waterways and areas around airports since it connects them with emerging, new infections as well as new strains of already familiar diseases (Guimera et al., 2005). Examples certify that the more accessible humans are, the more efficient is the vector that transmit the disease (Rodrigue et al., 2020); indeed, humans can themselves act as vectors as they transmit the novel coronavirus disease that emerged in 2019 (COVID19) from one person to another. Air transportation critically accelerate the spread of infections worldwide, while roads and rails, including mass transit and freight corridors, can effectively disseminate infections across cities and countries (Ballard, 2020). With the advent of truly global travel, the past 500 years have provided numerous examples of how the establishment and expansion of worldwide transport networks have facilitated global threats, such as the human immunodeficiency virus (HIV), cholera and bubonic plague as well as various mosquito-borne viral infections (Tatem et al., 2006). From the end of the $19^{\text {th }}$ century, the world has experienced six diseases classified as pandemics (Bergquist and Stensgaard, 2020), five of them types of influenza and the sixth COVID-19, which is caused by the severe acute respiratory syndrome-related coronavirus 2 (SARS-CoV-2). This disease originated in the Wuhan region of China in late November 2019 (Ma, 2020) and spread rapidly, first in China and then around the world, reaching 60 million cases within a year after its discovery and exceeding 80 million a month later (https://www.worldometers.info/coronavirus/).

Diffusion is the net movement of phenomena between regions on Earth's surface, and infectious diseases tend to follow the connections used by transport vehicles. The risk of infection depends on people's proximity to modern transport networks (accessibility) that inadvertently carry communicable diseases (Rodrigue et al., 2020). COVID-19 may be spread in various way, such as by expansion and relocation, or through contagious, hierarchical, transport networks and mixed diffusion (Hafsa, et al., 2020). However, global transport chains are of particularly importance as conceptually presented in Figure 1.

The three first cases of COVID-19 in Bangladesh was reported on 8 March 2020 (Reuters, 2020) and by 30 November 2020, it 
was reported that 316,728 positive COVID-19 cases had been diagnosed in the Dhaka division (WHO, 2020), making Bangladesh the second most affected area in South Asia after India at that time. As much as $53 \%$ of the total number of those infected in the country live in the district of Dhaka, while $65 \%$ the population in Dhaka City are infected (Hafsa, et al., 2020).

The smallest administrative units in Bangladesh is the union, several of which make up a sub-district, the upazila. One of these, Savar Upazila in the north-eastern part of Dhaka, was chosen for this study of COVID-19 development in relation to a major highway, the national Dhaka-Aricha highway (N5) that passes through this sub-district, where the first COVID-19 case occurred on 14 April 2020 (Dhaka Tribune, 2020). A report published by Upazila Health Complex (UHC) where the Family Planning Officer on 8 July 2020 noted the presence of 1040 cases diagnosed as positive for COVID-19. His report of this date also confirmed the death of twenty-six (26) COVID-19 patients in Savar Upazila. By this time, the UHC had reported a total number of 5783 active infections and 1014 former patients, who had recovered from the disease.

This study was initiated as it was felt to be important to mitigate the negative effects of the role played by the transport network and its results could thus be helpful for management of the current pandemic situation. The broad aim was to examine the relationship between COVID-19 and the transport network and accessibility areas in Savar Upazila by exploring the hypothesis that people in a high-accessibility zone would be more vulnerable compared to a low-accessibility one. It was felt that better knowledge about the disease could provide a window on the spread of COVID-19 in Bangladesh and thereby assist the development of policy developments. To achieve this goal, the following specific objectives were considered: i) to provide a map of the road network of Savar Upazila and measure the current COVID-19 infections; and ii) to assess the relationship between COVID-19 and the accessibility to infection potentially advanced by the local transport network.

Although transport generates value by linking regions and economic activities, as well as people, it also amplifies the spread of disease and is now directly responsible for the rapid expansion of the corona virus in many places via inadvertent transfer by people involved with shipments of goods. It must therefore be deemed one of the world's principal disease vectors and we focus here on this aspect.

\section{Materials and methods}

The concept used to follow the spread of COVID-19 is presented in Figure 2, which depicts how passenger and freight as well as information move through the road system on demand. It also shows how infectious diseases can spread in relation to this phenomenon, which can be seen as a system composed of core components, which are the modes, infrastructures, networks and flows (Rodrigue et al., 2020).

\section{Study area}

Savar Upazila is situated in a suburban fringe area in northeast Dhaka City. It is traversed by N5, the prominent highway that connects Dhaka City with northern Bangladesh. This sub-district is geographically located between coordinates $23^{\circ} 44^{\prime}$ and $24^{\circ} 02^{\prime} \mathrm{N}$ and $90^{\circ} 11^{\prime}$ ' and $90^{\circ} 22^{\prime} \mathrm{E}$ and occupies an area of $283 \mathrm{~km}^{2}$, including $20 \mathrm{~km}^{2}$ of river and $8 \mathrm{~km}^{2}$ of forest. The population number, provided by the Bangladesh Bureau of Statistics was 587,041 in 2011. Savar Upazila has a rapid population growth rate and has experienced changes of its traditional agrarian land use during the last few decades due to rapid urbanization and industrialization (Sultana et al., 2017). The length of N5 through the sub-district is about $30 \mathrm{~km}$, and its construction has triggered a massive change
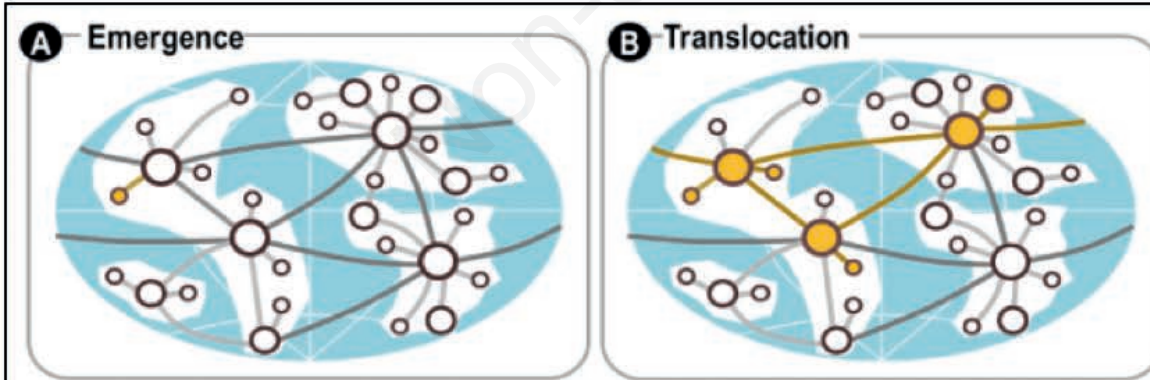

C Diffusion-
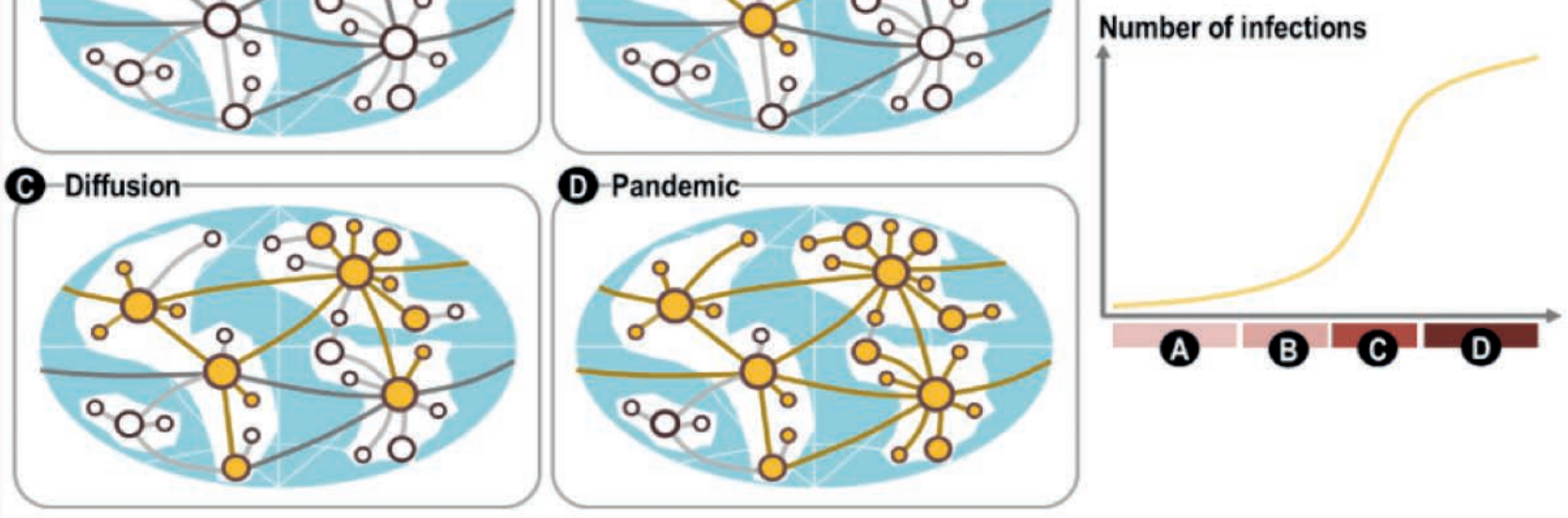

Figure 1. Passage of a pandemic infection through a global transport network. After Rodrigue et al. (2020). 
of the landscape (Amin, 2009). Today, it serves as the main traffic artery for northern transport from Dhaka City.

The sub-district consists of 13 unions (Figure 3) with five of them (Amin Bazar, Tetuljhora, Savar Paurashava, Savar and Pathalia) in close contact with the N5 highway, which increases the risk COVID-19 infection. Infrastructures, such as Jahangirnagar University, National Memorial, Savar Cantonment and Savar Dairy Farm are notable landmarks in the Pathalia union, while the Military Dairy Company, a radio station and a local bank are found along the N5 in Savar Paurashava, the administrative part of the sub-district.

\section{Approach}

The project undertaken rests on data from the local health facility - the Upazila Health Complex (UHC). By 8 July 2020, UHC had recorded 5783 COVID-19 samples: 1040 active cases, 26 deceased victims and 1014 persons, who had recovered from the disease (Table 1). The road network data of the study area was extracted by application of Google Earth. The images were georeferenced and digitized using ArcMap (ESRI, Redlands, CA, USA) and saved as shape files.

To connect these two sources of information, we applied a methodology based on road network accessibility analysis according to graph theory (Saxena, 2005). The next step included statistical treatment of the data followed by presentation of the output in the form of maps. Figure 4 summarizes the steps taken.

Transport networks are highly complex, spatial systems that are preferably analysed by graph theory. The analysis relies on the development of topological maps, which assist understanding how transport networks works by reducing spatial connections to its simplest format (Kansky, 1963). Figure 5 depicts the topological transformation of actual routes in the sub-district into characteristic connections, which do not rely so much upon distances and directions as on contiguity, relative locations and systematization of junctions. In applying graph theory to our study area, it was necessary to idealize the road network into a graph providing measures of the structural properties of a real-world system as a set of points (vertices or nodes) connected by a set of line segments

Table 1. Outcome of COVID-19 infections in Savar Upazila.

\begin{tabular}{lcccc} 
Number & Union & Infected & Recovered & Deceased \\
1 & Dhamsana & 101 & 98 & 3 \\
2 & Tatuljhora & 97 & 94 & 3 \\
\hline 3 & Ashulia & 98 & 98 & 0 \\
4 & Aminbazar & 5 & 5 & 0 \\
\hline 5 & Yearpur & 25 & 25 & 0 \\
6 & Pathalia & 53 & 51 & 2 \\
\hline 7 & Banagram & 11 & 11 & 0 \\
8 & Bhakurta & 0 & 0 & 0 \\
\hline 9 & Kaundia & 2 & 0 & 2 \\
10 & Savar & 216 & 216 & 0 \\
\hline 11 & Savar Paurashava & 423 & 407 & 16 \\
12 & Biralia & 5 & 5 & 0 \\
\hline 13 & Shimulia & 4 & 4 & 0 \\
Total & Savar Upazila & 1040 & 1014 & 26 \\
\hline
\end{tabular}

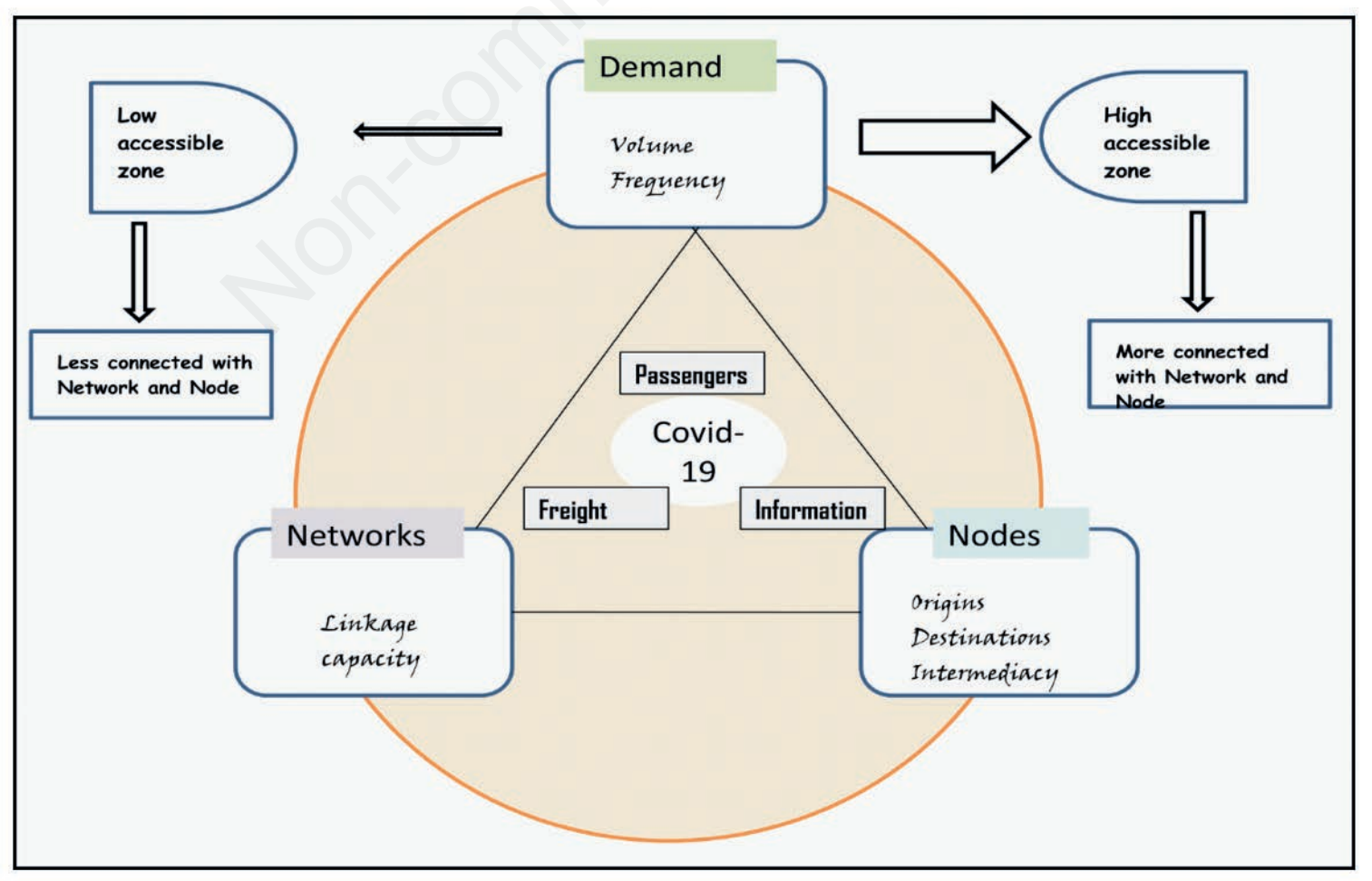

Figure 2. Relationship between an infectious disease and transport accessibility. 
(edges or arcs). A regional transport system is a combination of point-to-point movements that occurs between an origin and a destination. These movements are the basis of traffic flows and responsible for their spatial arrangements. In transport networks, the elements to be identified are:

- Vertices (v): the points which form the basic elements of a graph are known as vertices and designated as nodes. These are locations at the junctions of two or more connecting lines (arcs). A node occurring at the end of an arc is known as an end-node.

- Edges (e): the lines connecting the nodes are edges or arcs designated as links representing routes (here roads) which link the nodes. Only one arc may link two nodes.

While Figure 5 presents the backbone of transport in the study area and Figure 6 shows how this system can be applied at a more detailed, structural level. This is needed for an understanding how a transport network appears when considering all different possibilities to join nodes at the union level.

\section{Accessibility}

The degree of COVID-19 transmission capacity depends on what the transport network in question determines in terms of accessibility. The outcome is influenced by four core components of the network, i.e. mode, infrastructure, network and flow (Rodrigue et al., 2020). Aircraft and ships are believed to be responsible for rapid expansion of communicable diseases via inadvertent transfer of them including the world's principal disease vectors, in the case of COVID-19 infected humans are also the vectors. Due to the high accessibility of transport systems, they play the role of a potent conveyer system, whether it concerns incubated humans in a swiftly moving aircraft covering great distances or insect vectors along rail tracks, roads or minor waterways spreading the infection at the national scale.

Any node connected to other nodes in a network is said to be accessible and this term is a key element of transport geography, indeed to geography in general, since it is a direct expression of

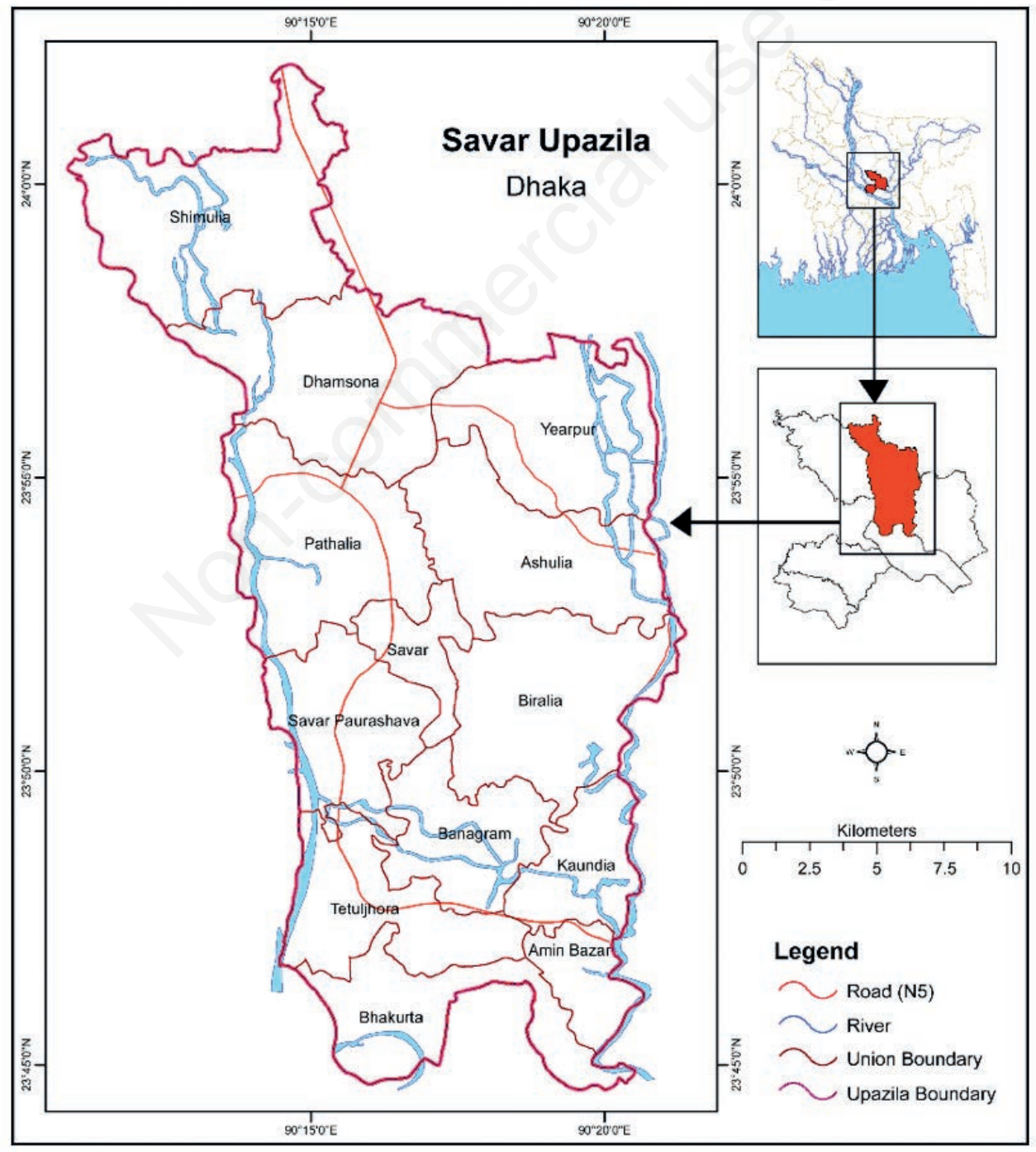

Figure 3. The study area - Savar Upazila with its 13 unions. 
mobility in terms of people, freight and information. Perceiving people as vectors of COVID-19 infection, we took an interest in the nodal accessibility as the nodes are meeting-points. High transport accessibility indicates high vulnerability to rapid spread of infection and low accessibility the opposite.

The degree of accessibility in the different parts of the study area were evaluated by taking the unions and their local municipality governments (the paurashavas) as main nodal points and measuring how well connected they are. Thus, the location of each node in the network of transport relative to other nodes bestow a particular measure of accessibility to them by virtue of their location; thus central nodes have a higher degree of accessibility compared to peripheral ones. The variation of the accessibility value over the study area was identified by means of two indices: i) the associate number; and ii) the Shimbel index, which can both be realized from an accessibility matrix, the number of rows and columns of which corresponds to the number of nodes in the network, while the matrix cells record information on the relationship between each pair of nodes (Figure 7). By convention, the horizontal rows are identified as origin nodes and the vertical columns as destination ones. From the topological graph in Figure 5, a shortest-path matrix connection for any pair of nodes can prepared. The matrix shown in Figure 7 gives the number of arcs forming the shortest path from any one union to any other.

The associate number is an aid to find the accessibility level of a transport network, where low numbers indicate high accessibility and high numbers the opposite, i.e. remoteness with low-level connections. The Shimbel accessibility index (Shimbel, 1951, 1963), also known as the D-Matrix, is derived from estimations of the relative distance from the point of origin to a destination (Arif and Gupta, 2020). Like the associate number, the lowest value of
Shimbel index indicates the most accessible node, while the highest specifies the least accessible one, which is found by counting the number of arcs needed to connect any pair of nodes in the network by the shortest paths.

\section{Statistics}

We applied Pearson correlation, or bivariate correlation, to measure the linear relation between accessibility and the presence of COVID-19 in the study area. The outcome of this statistic can vary between +1 and -1 , where the former indicates total positive correlation, 0 equals none and -1 total negative correlation.

We also carried out an analysis based on ArcGIS (ESRI) and Getis-Ord Gi* (Getis and Ord, 1992) statistic to investigate the potential presence of clustering in the study area. This approach requires results to be interpreted within the context of a null hypothesis, i.e. no spatial clustering of the values. This hypothesis can only be rejected when the P-value is statistically significant and when this occurs the z-score becomes important. A positive $\mathrm{z}$ score is an indication that high values for the attribute in question are clustered in the study area.

\section{Results}

Table 1 and Figure 7 show all the associate numbers and Shimbel indices of the study area. Aminbazar, Kaundia, Banagram, Bhakurta, Tetuljhora, Biralia, Ashulia, Pathalia, Dhamsana, Yearpur and Shimulia have high associate numbers $(>4)$, while Savar and Savar Pourasava have low ones $(\leq 4)$. With respect to the Shimbel approach, Savar Pourasava has the highest accessibility of all nodal points (Shimbel index=27), while Yearpur, Shimulia and
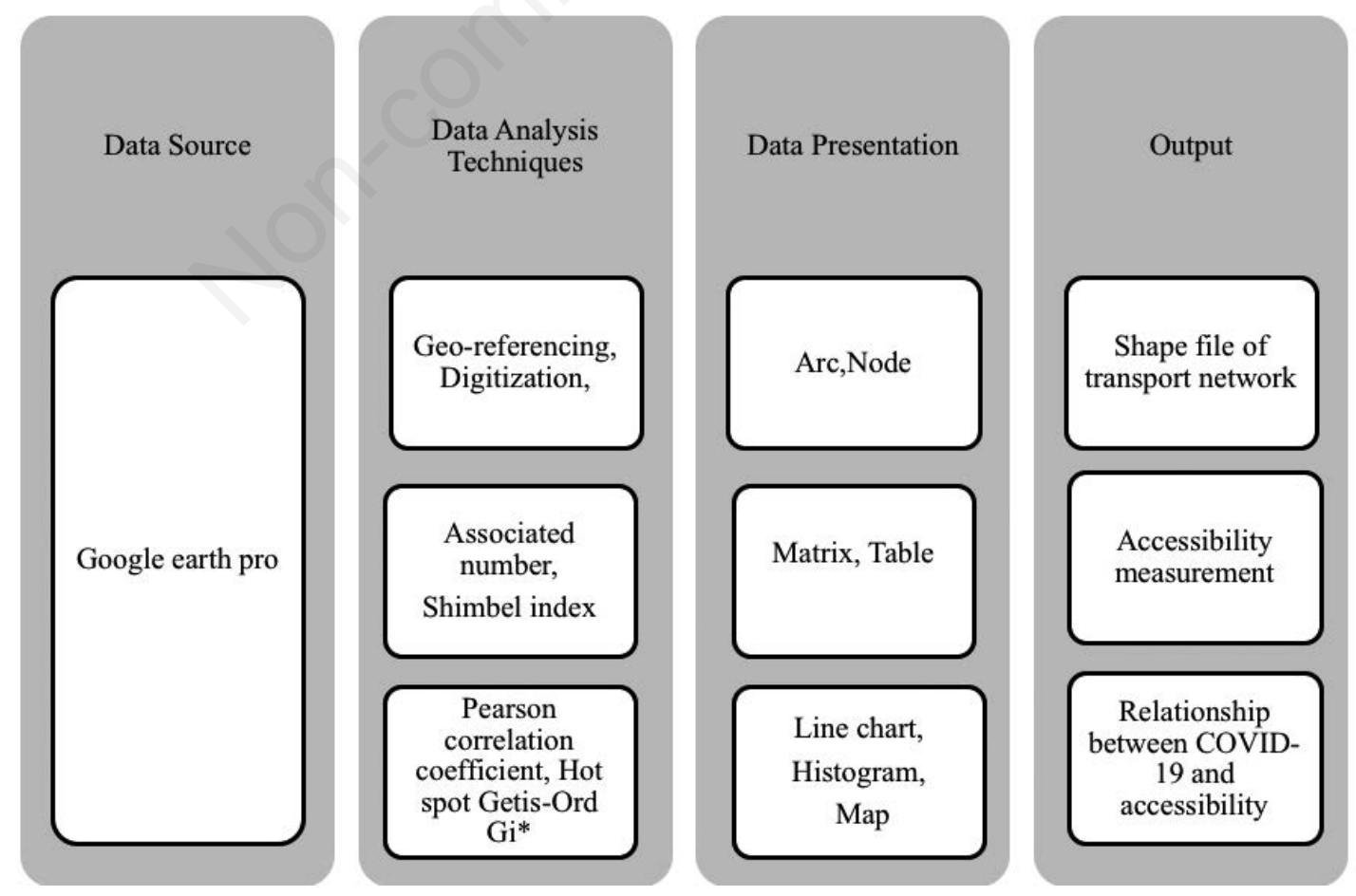

Figure 4. Overview of the study approach. 
Aminbazar show less accessibility by this shortest-path analysis, since they are located in the periphery. Thus, the most accessible zone in the study area is Savar Pourasava, which constitute the hub and also in close contact with the N5 highway (Table 2).

On the basis of the Shimbal matrix (Figure 7), the 13 nodal unions can be divided into five categories, where the first two are directly connected with N5: i) nodal centres with very high accessibility $(<28)$, which included only one union, namely Savar Pourasava; ii) nodal centres with very high accessibility (28-33), which included Savar (28), Teloljhora (30) and Pathalia (31); iii) nodal centres with moderate accessibility (34-39), which included Ashulia (38), Biralia (38) and Kaundia (39); iv) less accessible nodal centres (40-46), which included Banagram (41), Bakurta (41) and Dhamsana (40). Located near the periphery of the Savar Upazila with limited access from the other centres resulted in high values; v) nodal centres with the lowest accessibility $(>46)$, which included Aminbazar (50), Yearpur (50) and Shimulia (51). Due to their peripheral location, these unions had limited access to the others and had therefore very high values. Shimulia, location in the
Table 2. Accessibility index of study area.

\begin{tabular}{lccc} 
Number & $\begin{array}{c}\text { Union in Savar } \\
\text { Uparalla }\end{array}$ & $\begin{array}{c}\text { Associate } \\
\text { number }\end{array}$ & $\begin{array}{c}\text { Shimbel } \\
\text { index }\end{array}$ \\
1 & Amin Bazar & 7 & 50 \\
2 & Kaundia & 6 & 39 \\
\hline 3 & Banagram & 6 & 41 \\
4 & Bhakurta & 6 & 41 \\
\hline 5 & Tetuljhora & 5 & 30 \\
6 & Savar Pourashava & 4 & 27 \\
\hline 7 & Biralia & 5 & 38 \\
8 & Savar & 4 & 28 \\
\hline 9 & Ashulia & 5 & 38 \\
10 & Pathalia & 5 & 31 \\
\hline 11 & Dhamsana & 6 & 40 \\
12 & Yearpur & 7 & 50 \\
\hline 13 & Shimulia & 7 & 51 \\
\hline
\end{tabular}

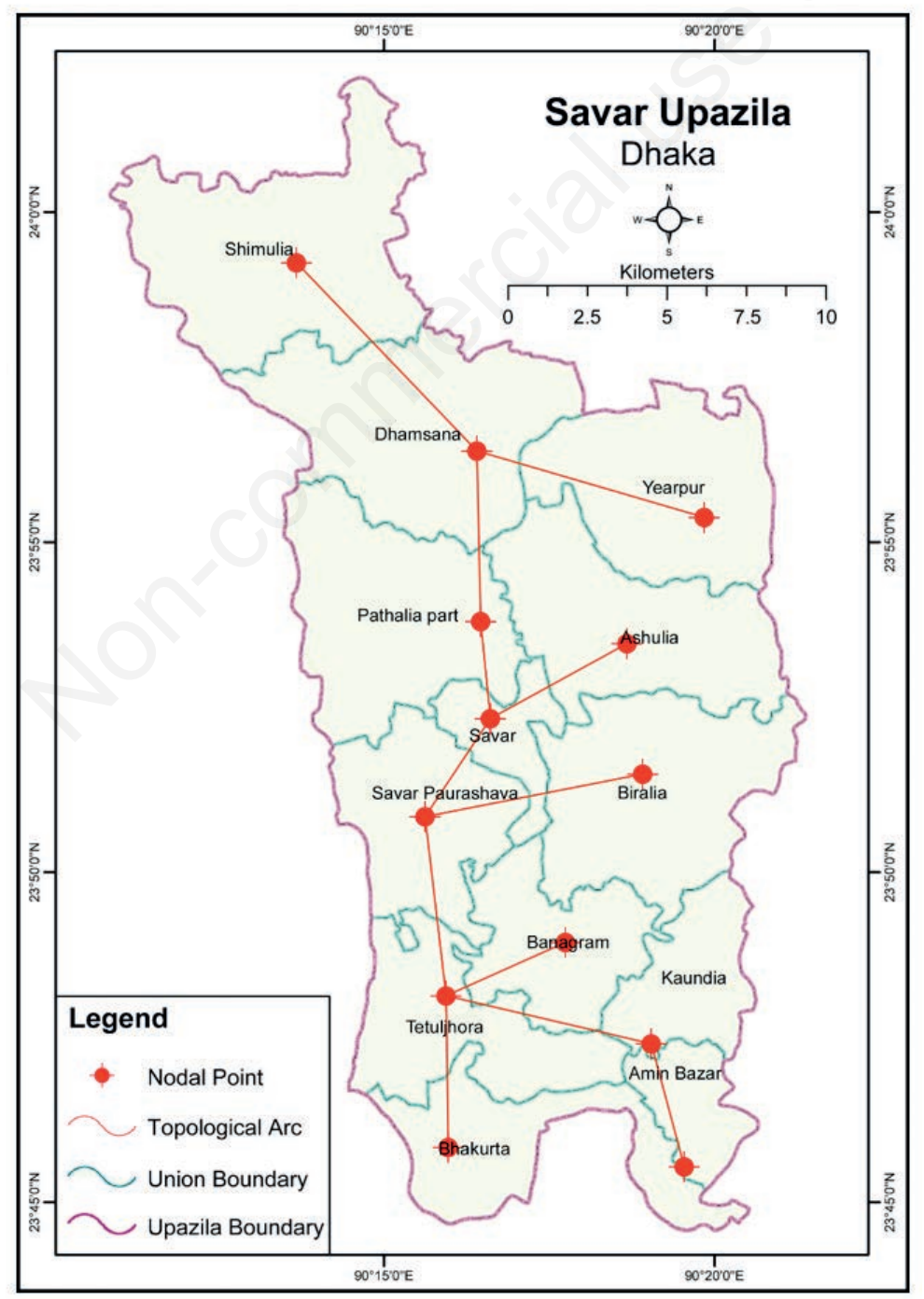

Figure 5. Topological map of the study area. 
far North made it the least accessible union.

Figures 8 and 9 reflect the distribution of infection and death due to COVID-19 in Savar Upazila. As can be seen both the highest number of infections and that of deaths (70\% of all mortality until 08/07/20 in the study area) occurred in Savar Paurashava (Health Emergency Operation Center, Government of the People's Republic of Bangladesh). Importantly, there is a close overlap between COVID-19 infections and areal accessibility as shown by Figure 10A and B, which clearly emphasize the strong connection of these two variables in Savar Paurashava.

The cluster analysis of COVID-19 in Savar Upazila revealed statistically significant hotspots, in particular in the Savar union and in Savar Pourashava [0.76 with 99\% confidence interval (CI)]. Similar but less pronounced hotspots were found in Dhamsuna, Ashulia, Tetuljhora. As can be seen, the strength of infection and presence of hotspots, all centred on Savar Pourashava. confirming that this union was indicated as the most vulnerable one by cluster analysis and infection proportion as well as infection density
(Figure 11). Importantly, these results are highly correlated with the accessibility map which shows highly accessible zones in both Savar Pourashava and Savar.

Table 3 represents the Pearson correlation between accessibility and infection by SARS-CoV-2 explaining the highly positive correlation present between accessibility and infection rate $(0.76)$. The zone of high accessibility is thus the most vulnerable.

Table 3. Correlation between node accessibility and COVID-19.

\begin{tabular}{lcc} 
& Accessibility & COVID-19 \\
Accessibility & 1 & 0.76 \\
COVID-19 & 0.76 & 1 \\
\hline
\end{tabular}

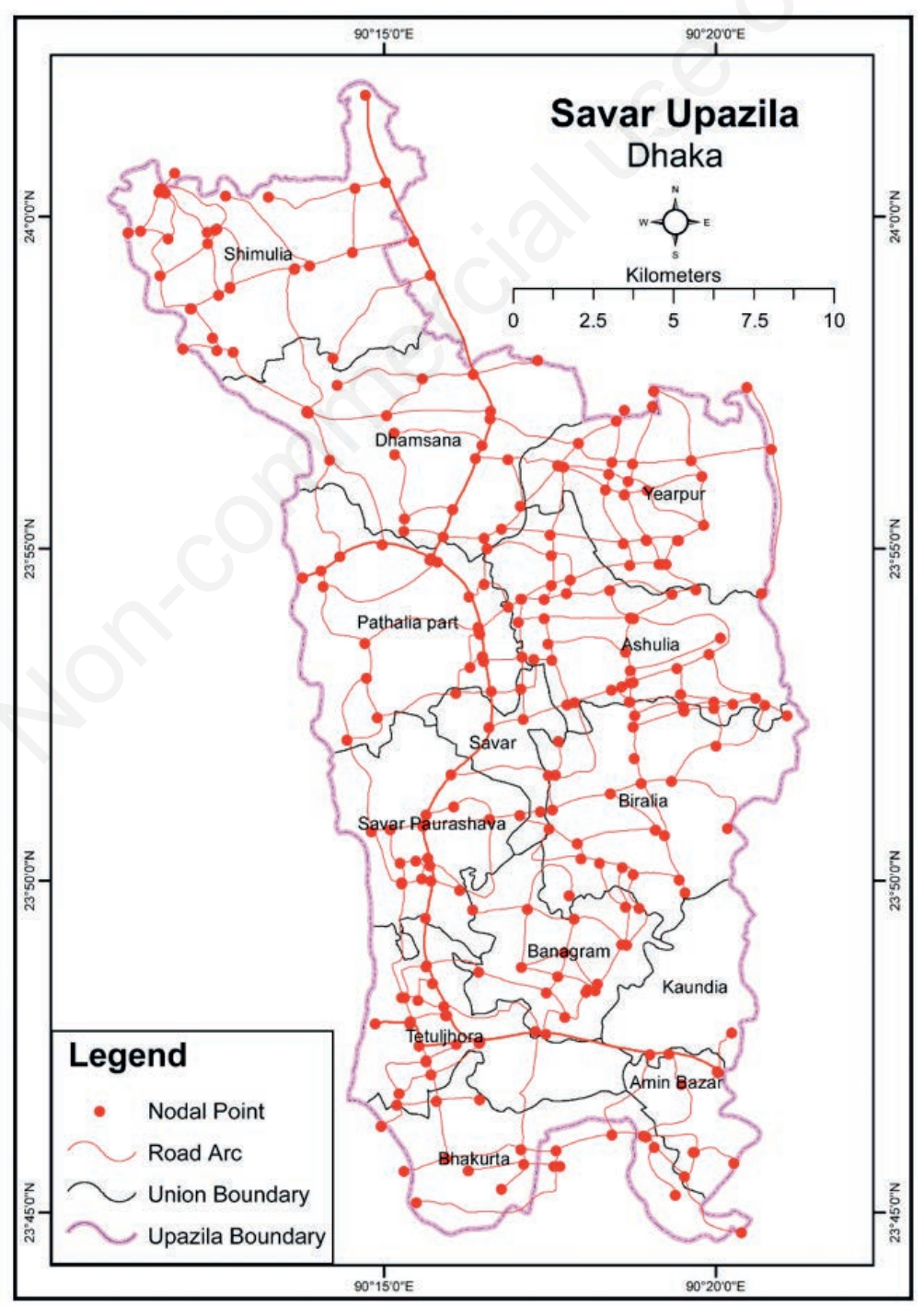

Figure 6. Structural network that joins the unions of study area in various ways depending on the availability of road connections. 


\begin{tabular}{|c|c|c|c|c|c|c|c|c|c|c|c|c|c|c|}
\hline Node & Amin Bazar & Kaundia & Banagram & Bhakurta & Tetuljhora & Savar $P$. & Biralia & Savar & Ashulia & Pathalia & Dhamsana & Yearpur & Shimulia & Total \\
\hline Amin Bazar & 0 & 1 & 3 & 3 & 2 & 3 & $\overline{4}$ & 4 & 5 & 5 & $\overline{6}$ & 7 & 7 & 50 \\
\hline Kaundia & 1 & 0 & 2 & 2 & 1 & 2 & 3 & 3 & 4 & 4 & 5 & $\frac{6}{6}$ & 6 & 39 \\
\hline Banagram & 3 & 2 & 0 & 2 & 1 & 2 & 3 & 3 & 4 & 4 & 5 & 6 & 6 & 41 \\
\hline Bhakurta & 3 & 2 & 2 & 0 & 1 & 2 & 3 & 3 & 4 & 4 & 5 & 6 & 6 & 41 \\
\hline Tetulihora & 2 & 1 & 1 & 1 & 0 & 1 & 2 & 2 & 3 & 3 & 4 & 5 & 5 & 30 \\
\hline Savar $P$. & 3 & 2 & 2 & 2 & 1 & 0 & 1 & 1 & 2 & 2 & 3 & 4 & 4 & 27 \\
\hline Biralia & 4 & 3 & 3 & 3 & 2 & 1 & 0 & 2 & 3 & 3 & 4 & 5 & 5 & 38 \\
\hline Savar & 4 & 3 & 3 & 3 & 2 & 1 & 2 & 0 & 1 & 1 & 2 & 3 & 3 & 28 \\
\hline Ashulia & 5 & 4 & 3 & 4 & 3 & 2 & 3 & 1 & 0 & 2 & 3 & 4 & 4 & 38 \\
\hline Pathalia & 5 & 4 & 4 & 4 & 3 & 2 & 3 & 1 & 2 & 0 & 1 & 2 & 2 & 33 \\
\hline Dhamsana & 6 & 5 & 5 & $\underline{5}$ & 4 & 3 & 4 & 2 & 3 & 1 & 0 & 1 & 1 & 40 \\
\hline Yearpur & 7 & 6 & 5 & 6 & 5 & 4 & 5 & 3 & 4 & 2 & 1 & $\underline{0}$ & 2 & 50 \\
\hline \begin{tabular}{|l|} 
Shimulia \\
\end{tabular} & 7 & 6 & 6 & 6 & 5 & $\overline{4}$ & 5 & 3 & $\overline{4}$ & 2 & 1 & 2 & 0 & 51 \\
\hline
\end{tabular}

Figure 7. Accessibility matrix. The proximity (shortest path) between any pair of nodes are given in the cell connecting the nodes (the associate number). The total value of all associate numbers in each row gives the Shimbel accessibility index for each node.

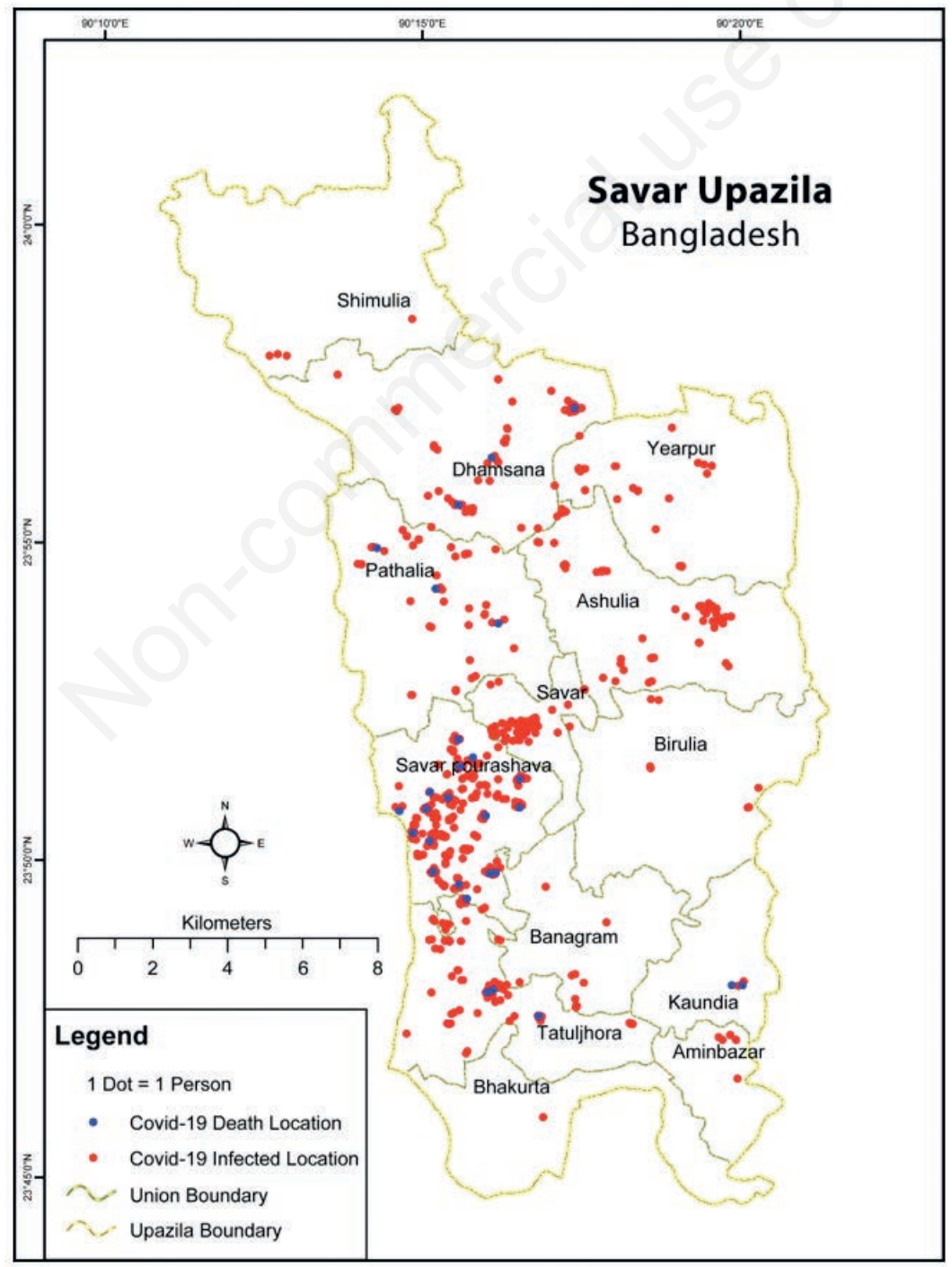

Figure 8. Overview of the distribution of COVID-19 infected and deceased people. 


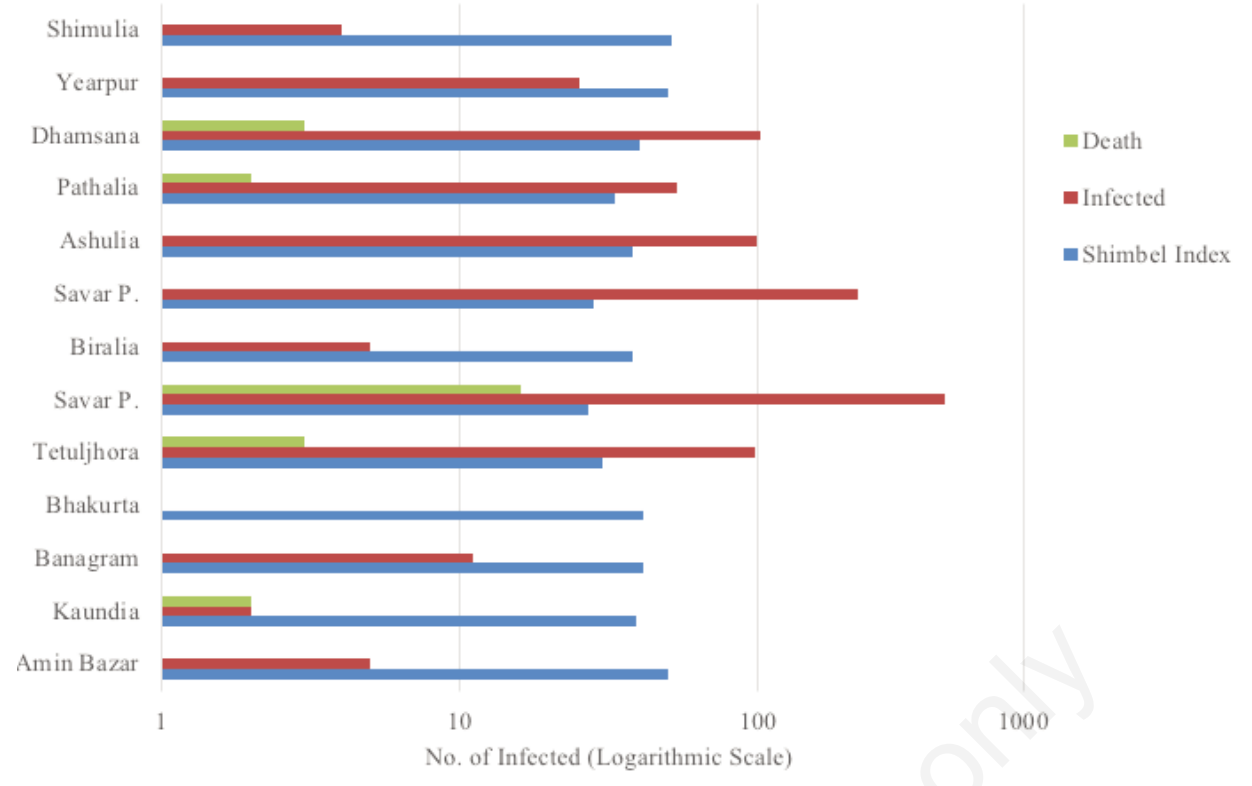

Figure 9. Relationship among accessibility, infection and death by COVID-19 in Savar Upazila.

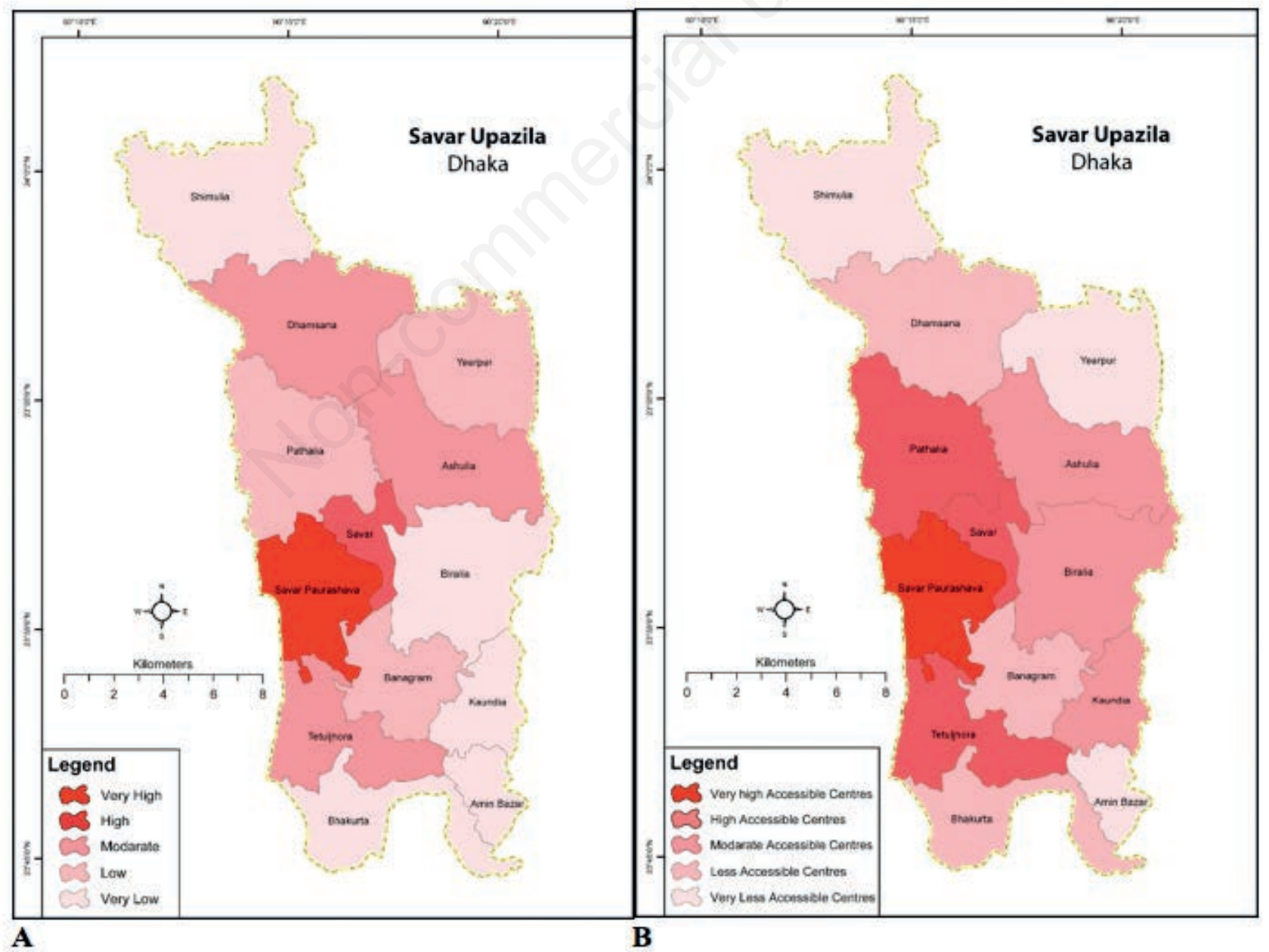

Figure 10. Distribution of infection and accessibility. A) Distribution of COVID-19; B) Accessibility based on the Shimbel index. 


\section{Summary of findings}

- Transport accessibility and COVID-19 were found to be positively correlated $(0.76$ with $99 \% \mathrm{CI})$.

- The highly accessible zone Savar Pourashava was the most

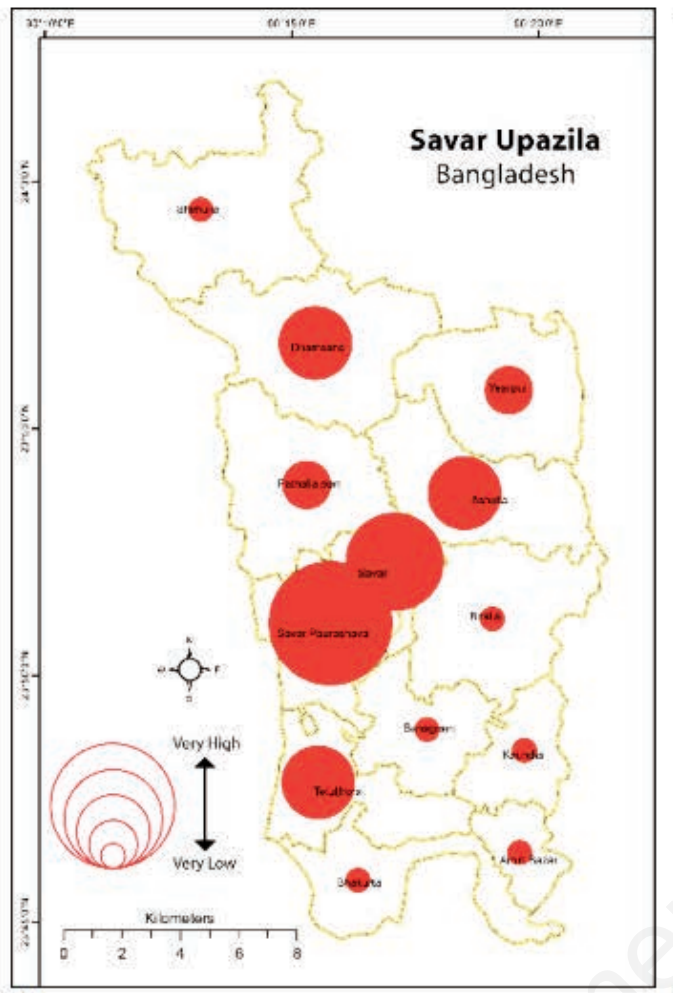

A

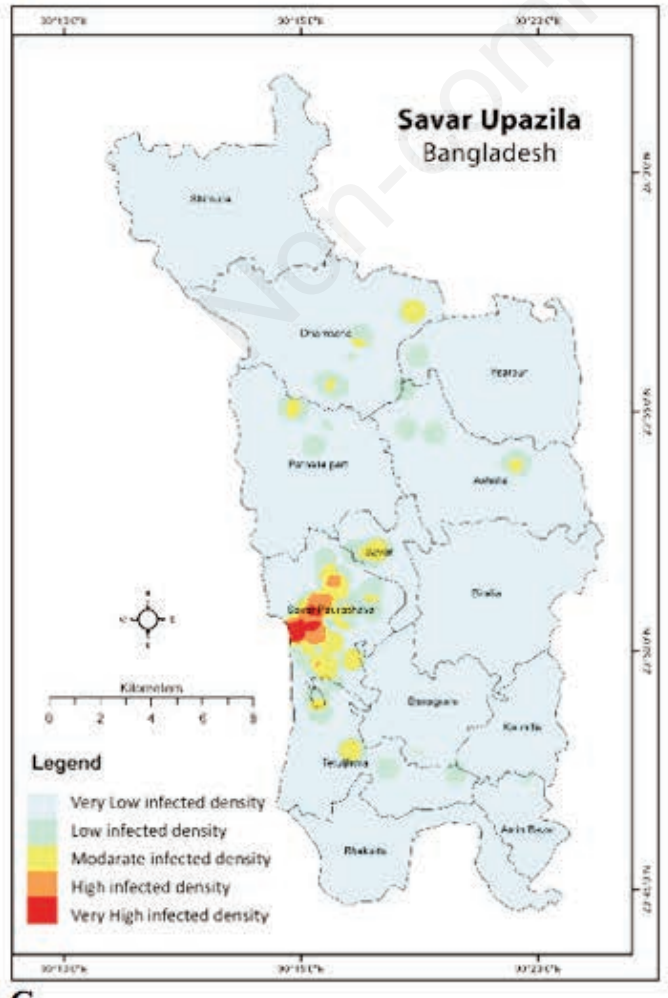

infected, while moderate accessible zones, such as the Tetholjhora and Ashulia unions, were moderately infected, and low accessible zones, such as Aminbazar and Shimulia unions, had only low rates of COVID-19 infection.

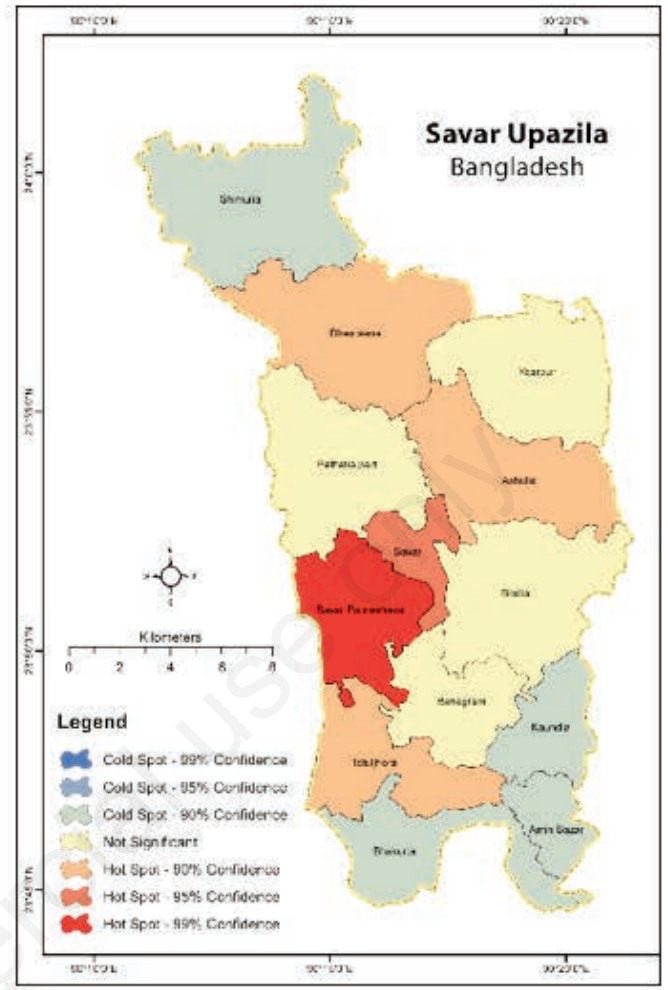

B

Figure 11. Infected proportion, hotspot and infected density map of COVID-19. A) Infected proportion; B) distribution of hotspots; C) distribution of infection density. 


\section{Discussion}

As a reflection of the movement of people, COVID-19 has spread around the world and become a pandemic. Due to all the various transport network system available today, this has occurred within less than three months after the first cases were found in Wuhan, China. This study expose the close relationship between transport networks and the spread of COVID-19 emphasizing the important role of the geographic transport chains. The results of the study support the hypothesis that people in high-transport zones are more vulnerable with respect to transmission of COVID19 than those in low transport ones because of the high accessibility offered by the concentration of people along limited areas of connection. The improved connectivity and accessibility revealed by the associate numbers and the Shimbel index emphasizes the pivotal role of Savar Pourashava in Bangladesh and its strong connection with the majority of the nodal points. This kind of areas attract people and goods, become larger and form town and cities in due course. The transport network accessibility deals with various kind of application of developments, but COVID-19 rapidly spread by movement of human and other things by dependence on transport. The number of confirmed infections of COVID-19 has increased geometrically and efforts to break the spread a strategy have not been successful. However, it has been possible to delay transmission to some degree by lockdown (home isolation, voluntary/required quarantine), social distancing (vulnerable or entire populations), closure of schools/universities and non-essential businesses/workplaces, cancelling or postponing events (i.e., major conferences and tradeshows, concerts and festivals, political debates and elections, sports seasons) and bans on gatherings. By stressing the importance of local and distant movements, this study may aid to develop better policies for infections like COVID-19.

Overall, this study has indicated the strong importance of transport networks in dissemination of this disease and it is expected that similar results would be found with regard to other communicable diseases. Thus, this work will be followed by future research on the role for transport networks for the spread of other diseases in other countries. It would also be useful to follow the development of transport networks over time.

\section{Conclusions}

Increased road transportation, local investment in industrial development and interaction are key reasons behind the economic growth in the region. The map analysis presented was carried out using topological abstraction of a local road network in Bangladesh, while the shortest-path matrix, associated numbers and the Shimbel index, revealed the nature of accessibility not only for the economy but also for its role in the spread of diseases. It is therefore important to consider how to mitigate the negative consequences of accessibility, while at the same time stimulating business interchange and growth.

\section{References}

Arif M, Gupta K, 2020. Application of graph-based model for the quantification of transport network in peri-urban interface of Burdwan City, India. Spat Inf Res 28:447-57.
Ballard M, 2020. How big of a factor were commuters in spreading coronavirus in Louisiana? Available from: https://www.theadvocate.com/baton_rouge/news/coronavirus/article_0c1164ce7d00-11 ea-a416-53129213c596.html Accessed: 12 April 2020.

Bergquist R, Stengaard A-S, 2020. COVID-19: End of the beginning? Geospat Health 15:6-10.

Dhaka Tribune, 2020. Savar confirms its first coronavirus case; 14 April 2020. Available from: https://www.dhakatribune. com/bangladesh/nation/2020/04/14/savar-confirms-its-firstcoronavirus-case Accessed: 14 April 2020.

Getis A, Ord JK, 1992. The analysis of spatial association by use of distance statistics. Geogr Anal 24:189-206.

Guimera R, Mossa S, Turtschi A, Amaral LAN, 2005. The worldwide air transportation network: anomalous centrality, community structure, and cities' global roles. Proc Natl Acad Sci U S A 102:7794-9.

Hafsa B, Mahmud KH, Ahmed R, 2020. COVID-19 cases in Savar Upazila of Bangladesh: a geographical inquiry. Glob Sci J 8:549-66.

Kansky KJ, 1963. Structure of transport networks: relationships between network geometry and regional characteristics. Dept. of Geography, University of Chicago, Chicago, IL, USA. Research Paper No. 84, pp. 155.

Ma J, 2020. Coronavirus: China's first confirmed COVID-19 case traced back to November 17. South China Morning Post of 13 March 2020. Available from: www.scmp.com

Reuters, 2020. Information given on 8 March 2020. Available from: https://www.reuters.com/article/us-health-coronavirusbangladesh-idUSKBN20V0FS Accessed: 20 January 2021.

Rodrigue JP, Luke T, Osterholm M, 2020. B.19 - Transportation and pandemics. In: J.-P. Rodrigue (Ed.), Geography of transport systems, $5^{\text {th }}$ edn. Routledge, New York, NY, USA, pp. 456.

Saxena HM, 2010. Transport geography. Rawat Publication, Jaipur and New Delhi, India, pp. 54-70.

Shimbel A, 1951. Applications of matrix algebra to communication nets. Bull Math Biophys 13:165-78.

Shimbel A, 1953. Structural parameters of communication networks. Bull Math Biophys 15:501-7.

Sultana N, Alam AKMR, HoqueS, 2017. Some physical and chemical characteristics of soil in selected wetlands at Savar, Bangladesh. Jahangirnagar University Environ Bull 6:13-26. Available from: https://www.researchgate.net/ publication/324419470_Some_Physical_and_Chemical_Characteristi cs_of_Soil_in_Selected_Wetlands_at_Savar_Bangladesh Accessed: 20 January 2021.

Taubenberger JK, Morens DM, 2020. The 1918 influenza pandemic and its legacy. Cold Spring Harb Perspect Med 10:a038695.

Tatem AJ, Hay SI, Rogers DJ, 2006. Global traffic and disease vector dispersal. Proc Natl Acad Sci U S A 103:6242-47.

WHO (World Health Organization), 2018 $\square$. Managing epidemics: key facts about major deadly diseases. World Health Organization, Geneva, Switzerland. Available from: https://apps.who.int/iris/handle/10665/272442

WHO (World Health Organization), 2020. Morbidity and mortality; 30 November 2020. Weekly update (MMWU). No. 40. World Health Organization, Geneva, Switzerland. Available from: https://www.who.int/docs/default-source/searo/ bangladesh/ COVID-19-who-bangladesh-situation-reports/who_COVID19-update_40_20201130. pdf?sfvrsn=3bb2e6fb_24 